\title{
Metabolic engineering of Aspergillus niger via ribonucleoprotein-based CRISPR- Cas9 system for succinic acid production from renewable biomass
}

\author{
Lei Yang ${ }^{1^{*}}$ (1), Mikkel Møller Henriksen ${ }^{1}$, Rasmus Syrach Hansen ${ }^{1}$, Mette Lübeck', Jesper Vang ${ }^{1,4}$,
} Julie Egelund Andersen², Signe Bille ${ }^{3}$ and Peter Stephensen Lübeck ${ }^{1}$

\begin{abstract}
Background: Succinic acid has great potential to be a new bio-based building block for deriving a number of value-added chemicals in industry. Bio-based succinic acid production from renewable biomass can provide a feasible approach to partially alleviate the dependence of global manufacturing on petroleum refinery. To improve the economics of biological processes, we attempted to explore possible solutions with a fungal cell platform. In this study, Aspergillus niger, a well-known industrial production organism for bio-based organic acids, was exploited for its potential for succinic acid production.

Results: With a ribonucleoprotein (RNP)-based CRISPR-Cas9 system, consecutive genetic manipulations were realized in engineering of the citric acid-producing strain A. niger ATCC 1015. Two genes involved in production of two byproducts, gluconic acid and oxalic acid, were disrupted. In addition, an efficient $\mathrm{C}_{4}$-dicarboxylate transporter and a soluble NADH-dependent fumarate reductase were overexpressed. The resulting strain SAP-3 produced $17 \mathrm{~g} / \mathrm{L}$ succinic acid while there was no succinic acid detected at a measurable level in the wild-type strain using a synthetic substrate. Furthermore, two cultivation parameters, temperature and $\mathrm{pH}$, were investigated for their effects on succinic acid production. The highest amount of succinic acid was obtained at $35^{\circ} \mathrm{C}$ after 3 days, and low culture pH had inhibitory effects on succinic acid production. Two types of renewable biomass were explored as substrates for succinic acid production. After 6 days, the SAP-3 strain was capable of producing $23 \mathrm{~g} / \mathrm{L}$ and $9 \mathrm{~g} / \mathrm{L}$ succinic acid from sugar beet molasses and wheat straw hydrolysate, respectively.

Conclusions: In this study, we have successfully applied the RNP-based CRISPR-Cas9 system in genetic engineering of $A$. niger and significantly improved the succinic acid production in the engineered strain. The studies on cultivation parameters revealed the impacts of $\mathrm{pH}$ and temperature on succinic acid production and the future challenges in strain development. The feasibility of using renewable biomass for succinic acid production by A. niger has been demonstrated with molasses and wheat straw hydrolysate.
\end{abstract}

Keywords: Aspergillus niger, Metabolic engineering, Succinic acid production, CRISPR-Cas9 system

*Correspondence: ly@bio.aau.dk

1 Section for Sustainable Biotechnology, Department of Chemistry and Bioscience, Aalborg University Copenhagen, A. C. Meyers Vænge 15, 2450 Copenhagen SV, Denmark

Full list of author information is available at the end of the article

\section{Background}

With increasing concerns on climate change and its adverse impacts on the natural environment as well as human society, development of biotechnology has been focusing on providing sustainable and 
environment-friendly solutions for global manufacturers of commodity chemicals, which heavily rely on oil refinery and give high greenhouse gas emission and environmental pollution. For the past decades, bio-based succinic acid production from renewable biomass has been one of the research hotspots in sustainable biotechnology due to the great potentials of succinic acid to be a building block for deriving varieties of commodity and specialty chemicals [1]. Furthermore, bio-based succinic acid production is also considered as a promising paradigm demonstrating the feasibility of using sustainable biological processes to replace petrol-based processes in the chemical industry [2]. With great efforts in process development and strain improvement, the price of succinic acid produced from biological processes using microbial strains (Actinobacillus succinogenes, Escherichia coli, and Saccharomyces cerevisiae) has been lowered to a competitive level compared with that produced via petrol-based processes [3, 4]. However, if the further application of succinic acid aims at becoming a new bio-based building block in chemical industry to produce commodity chemicals, such as 1,4-butanediol and biodegradable polymers, the current price is still too expensive, which demands further improvement on the economics of biological processes. Production strains are of great importance to process development for bio-succinic acid production. The performance of microbial strains does not only determine the process productivity, but also influences the choice of feedstock and designing of downstream processes involving product purification. Although a number of biological processes have successfully been commercialized with bacterial and yeast strains, some limitations have also been exposed in these strains, which restrict the strain improvement on several key limiting factors in succinic acid production. Among limiting factors are utilization of cheap substrates, yield and productivities of succinic acid, and tolerance of stress conditions, including $\mathrm{pH}$ and other potential inhibitors $[5,6]$. In order to break through the technical bottlenecks, more research attention has been directed on exploitation of new microbial platforms for bio-succinic acid production $[7,8]$.

In the history of microbial production of organic acids, Aspergillus niger has been well known as a successful industrial workhorse for bio-based production of citric acid. It possesses a number of virtues that greatly facilitate development of biological processes for organic acid production, e.g., efficient secretion of organic acids, excellent capabilities of utilizing varieties of cheap feedstock, high tolerance to stress conditions, e.g., low $\mathrm{pH}$ and heavy metals [9-12]. Therefore, A. niger has been considered to be the top candidate for the production of other organic acids, e.g., lactic acid, itaconic acid, and malic acid [13-15]. However, succinic acid production by $A$. niger has been explored with little success. Earlier studies on metabolic engineering of $A$. niger have focused on the major metabolic routes that are involved in efficient production of succinic acid by other microorganisms (e.g., reductive tricarboxylic acid (rTCA) branch and glyoxylate bypass). Genetic modifications on these pathways did not lead, however, to an overflow of carbon flux toward succinic acid production [16, 17]. On the other hand, the mechanisms of efficient excretion of organic acids has not been fully understood in $A$. niger, which increases the difficulties in rerouting the carbon flux toward succinic acid from other major organic acids using pathway engineering. In our previous studies, we have identified a key limiting step for $\mathrm{C}_{4}$-dicarboxylic acid production in another black aspergillus, $A$. carbonarius, which highly resembles $A$. niger in the organic acid profile [18]. After identifying and overexpressing the native membrane protein AcDCT in A. carbonarius, $\mathrm{C}_{4}$-dicarboxylic acid production, including malic acid and succinic acid, increased significantly [19]. Another recent study on $A$. niger reported that, efficient production of malic acid was obtained with overexpression of a number of genes related to the cytosolic rTCA branch [15]. These findings imply the high possibility of improving succinic acid production by $A$. niger by continuing carbon flux towards succinate in the cytosolic pathway. Therefore, to test this hypothesis, we chose to express a soluble NADH-dependent fumarate reductase (FRD), which has previously been expressed in a natural malic acid-producing strain of Aspergillus saccharolyticus and successfully enhanced production of succinic acid [20], in combination with other genetic modifications in A. niger, and evaluated their impacts on succinic acid production (Fig. 1).

Lack of efficient genetic tools has always been a major obstacle to hinder genetic engineering of $A$. niger strains. Although stable ectopic expression of genes in $A$. niger can be achieved with integrative expression vectors, precise genome editing, e.g., gene targeting, remains difficult due to the naturally low homologous recombination frequency in A. niger [21]. Moreover, the consecutive genetic manipulations, which are normally required in pathway engineering, are hardly achieved in $A$. niger due to the lack of selectable markers and a time-consuming marker recycling process. Recently, successful applications of the CRISPR-Cas9 system in filamentous fungi have inspired development of novel genome editing tools for A. niger, and so far, two types of CRISPR-Cas9 systems have been applied in genetic engineering of $A$. niger. First, an expression-based system using a plasmid vector, which consists of elements for expressing the Cas9 protein and transcription of gRNA in vivo was developed [22]. Then, a ribonucleoprotein (RNP) based system using 


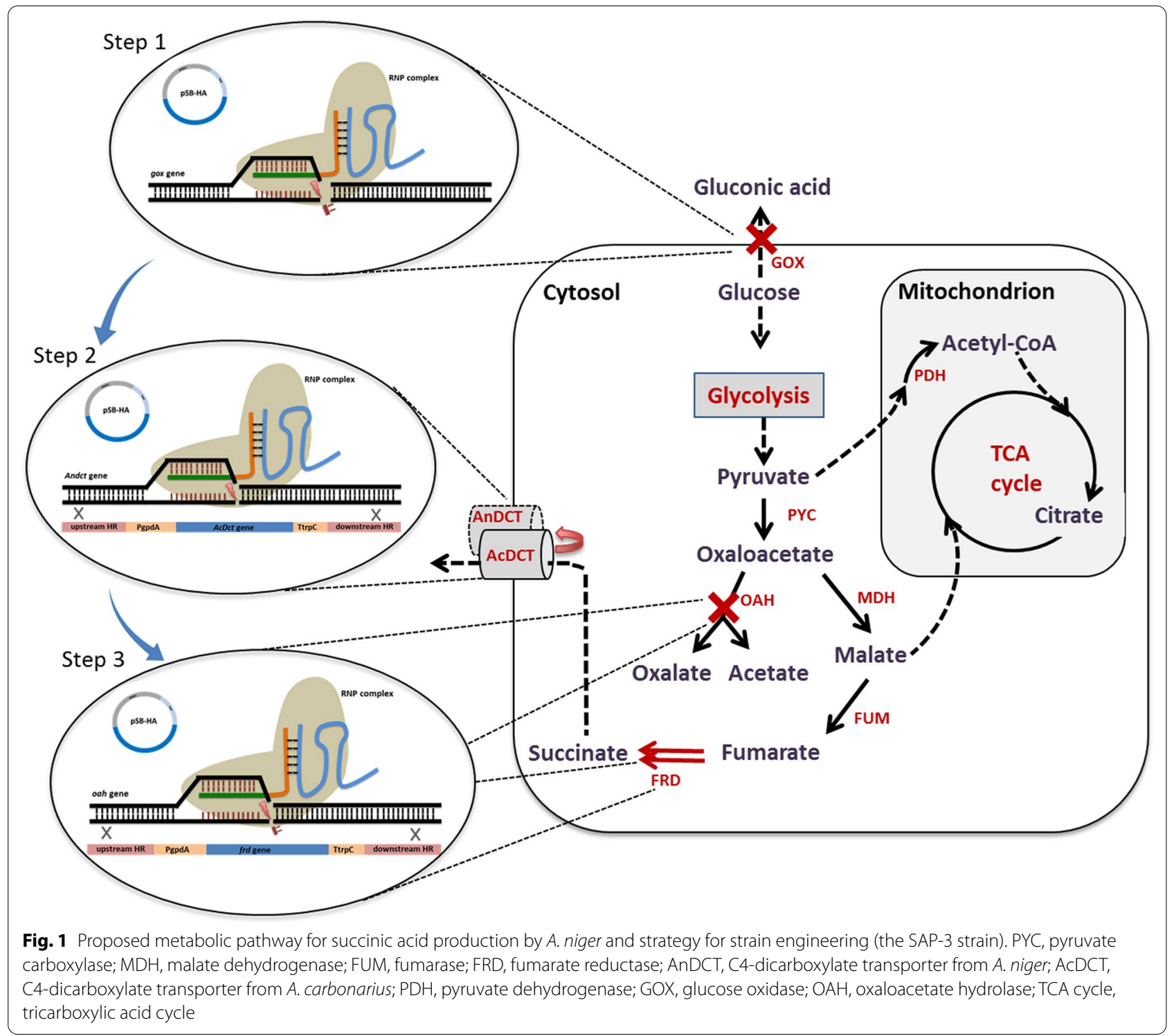

in vitro assembly of Cas9 protein and synthetic gRNA into a RNP complex, which in turn is applied directly into the protoplast transformation of $A$. niger, was developed [23]. The early-developed expression-based system is restricted to efficient in vivo transcription of gRNA since the stable gRNA products were achieved by expressing a self-cleaved ribozyme-gRNA cassette under regulation of a Pol II promoter [22]. Recently, tRNA promoters have been identified in $A$. niger and applied in transcription of gRNA without ribozyme splicing sequences. However, since the expression of Cas9 protein and gRNA transcription take place in the cell, it is difficult to control the assembly process of Cas9 and gRNA in vivo, which may lead to higher off-target events in the later stage [24]. On the other hand, the RNP-based system adopts the purified Cas9 protein and synthetic gRNA, so it can reach a precise control of gRNA and Cas9 protein in terms of concentrations and provide the optimal reaction conditions for in vitro assembly, which can lower the risk of off-target events. However, although a RNP complex can be used directly in genome editing of $A$. niger, the system naturally lacks a selectable marker for fungal transformation processes. Therefore, the RNP complex is normally used with an additional integrative vector containing marker genes for selection of transformants [25]. In this study, we attempted to use a recyclable marker system together with the RNP complex to realize easy and fast consecutive genetic manipulations in A. niger. By evaluating the performance of the engineered strains, we aimed to demonstrate the feasibility of applying $A$. niger 
as a novel platform for bio-based production of succinic acid from renewable biomass.

\section{Results}

Strain engineering via RNP-based CRISPR-Cas9 system

In this study, all the genetic modifications were introduced via the CRISPR-Cas9 RNP-based system. The selectable marker was located in the episomal vector pSB-HA containing the AMA1 sequence and transferred separately with RNP complex into fungal cells via protoplast transformation. For single gene disruption, null mutations were introduced into the gox and oah genes via non-homologous end joining (NHEJ) repair pathway after CRISPR-Cas9-mediated DNA double-strand breaks. The gene disruption efficiency reached $37.5 \%$ for the gox gene and $12.5 \%$ for the oah gene. For gene replacement, a donor DNA fragment containing homologous regions (HR) and gene expression cassette were used in addition to the vector $\mathrm{pSB}$-HA and RNP complex in the transformation. As seen in Table 1, two out of 24 transformants were verified for the successful replacement of the Andct gene with the Acdct gene expression cassette, and two out of 11 transformants had the frd expression cassette integrated into the oah gene, which yielded efficiencies of $8.3 \%$ and $18 \%$, respectively.

\section{Succinic acid production by engineered strains}

Comparison of succinic acid production by the engineered strains was performed in the defined glucose medium with $\mathrm{CaCO}_{3}$ as a pH-buffering reagent. All the strains had pellet morphology during the cultivation (Additional file 1: Table S1). As seen in Fig. 2, the wild type was not capable of producing detectable amount of succinic acid during the cultivation, while most of the glucose was consumed and rapidly converted into gluconic acid $(0.53 \mathrm{~g} / \mathrm{g}$ glucose $)$ after 3 days. In the engineered strains, the SAP-1 strain consumed the lowest amount of glucose after 4 days with significantly lower production of organic acids than the other strains (Fig. 2a, c). However, the SAP-1 strain produced a low amount of succinic acid $(0.99 \mathrm{~g} / \mathrm{L})$ after 4 days. In the SAP-2 strain, overexpression of Acdct gene led to an emergence of succinic acid production in earlier stages of the cultivation and higher amounts of succinic acid production $(5.2 \mathrm{~g} / \mathrm{L})$ compared with the SAP-1 strain. Furthermore, co-overexpression of the Acdct gene and the frd gene in the SAP-3 strains resulted in more than threefold increase in succinic acid production than that of the SAP-2 strain, and $17 \mathrm{~g} / \mathrm{L}$ succinic acid was obtained after 4 days (Fig. 2b). On the other hand, the SAP-3 strain consumed glucose more rapidly than the two other engineered strains, but yielded lower fungal biomass. In an overview of organic acid profiles by the engineered strains, citric acid and malic acid were also produced as major organic acid products in addition to succinic acid. Compared with the wild-type strain, citric acid production was not affected significantly with different genetic modifications, but malic acid production increased in all the engineered strains. However, the yield of malic acid decreased in the SAP-3 strain with overexpression of the frd gene compared with the SAP-2 strain (Fig. 2c).

\section{Impacts of temperature and $\mathrm{pH}$ on succinic acid production}

The impact of different temperatures on succinic acid production was investigated by cultivating the SAP-3 strain with the defined glucose medium in shake flasks. Four different temperatures, $25,30,35$ and $40{ }^{\circ} \mathrm{C}$ were chosen within the optimal range for the growth of $A$. niger. All the cultures had a similar $\mathrm{pH}$ level on day 3 under different cultivation temperatures (Additional file 1: Table S2). As seen in Fig. 3a, the glucose consumption showed positive correlation with the temperature increase after day 1 . The SAP-3 strain consumed all the glucose at $40{ }^{\circ} \mathrm{C}$ after 3 days, whereas $62 \mathrm{~g} / \mathrm{L}$ glucose remained in the culture at $25{ }^{\circ} \mathrm{C}$. In terms of succinic acid production, the highest amount and yield $(17 \mathrm{~g} / \mathrm{L}$ and $0.18 \mathrm{~g} / \mathrm{g}$ glucose) were obtained at $35{ }^{\circ} \mathrm{C}$ on day 3 (Fig. 3b, c). The yield of succinic acid at $30{ }^{\circ} \mathrm{C}$ reached $0.17 \mathrm{~g} / \mathrm{g}$ glucose, which was close to the yield at $35^{\circ} \mathrm{C}$, but the sugar consumption and the amount of succinic acid was lower. In contrast, the highest amount of succinic acid was obtained at $40{ }^{\circ} \mathrm{C}$ on day 2 due to the more rapid sugar consumption, but the final yield of succinic acid was lower after 3 days than at $35^{\circ} \mathrm{C}$. On the other hand, the low temperature at $25^{\circ} \mathrm{C}$ benefitted the fungal

Table 1 Efficiency of RNP-based CRISPR-Cas9 system for genetic modifications

\begin{tabular}{|c|c|c|c|c|}
\hline Genetic modification & $\begin{array}{l}\text { Total number } \\
\text { of transformants }\end{array}$ & $\begin{array}{l}\text { Number of correct } \\
\text { transformants }\end{array}$ & Efficiency (\%) & $\begin{array}{l}\text { Corresponding } \\
\text { engineered } \\
\text { strains }\end{array}$ \\
\hline$\Delta g o x$ & 8 & 3 & 37.5 & SAP-1 \\
\hline$\Delta o a h$ & 16 & 2 & 12.5 & SAP-1 \\
\hline$\triangle A n D c t:: G P D A p-A c D C T-t T r p C$ & 24 & 2 & 8.3 & SAP-2 \\
\hline$\triangle o a h:: G P D A p-f r d-t \operatorname{Tr} P C$ & 11 & 2 & 18 & SAP-3 \\
\hline
\end{tabular}



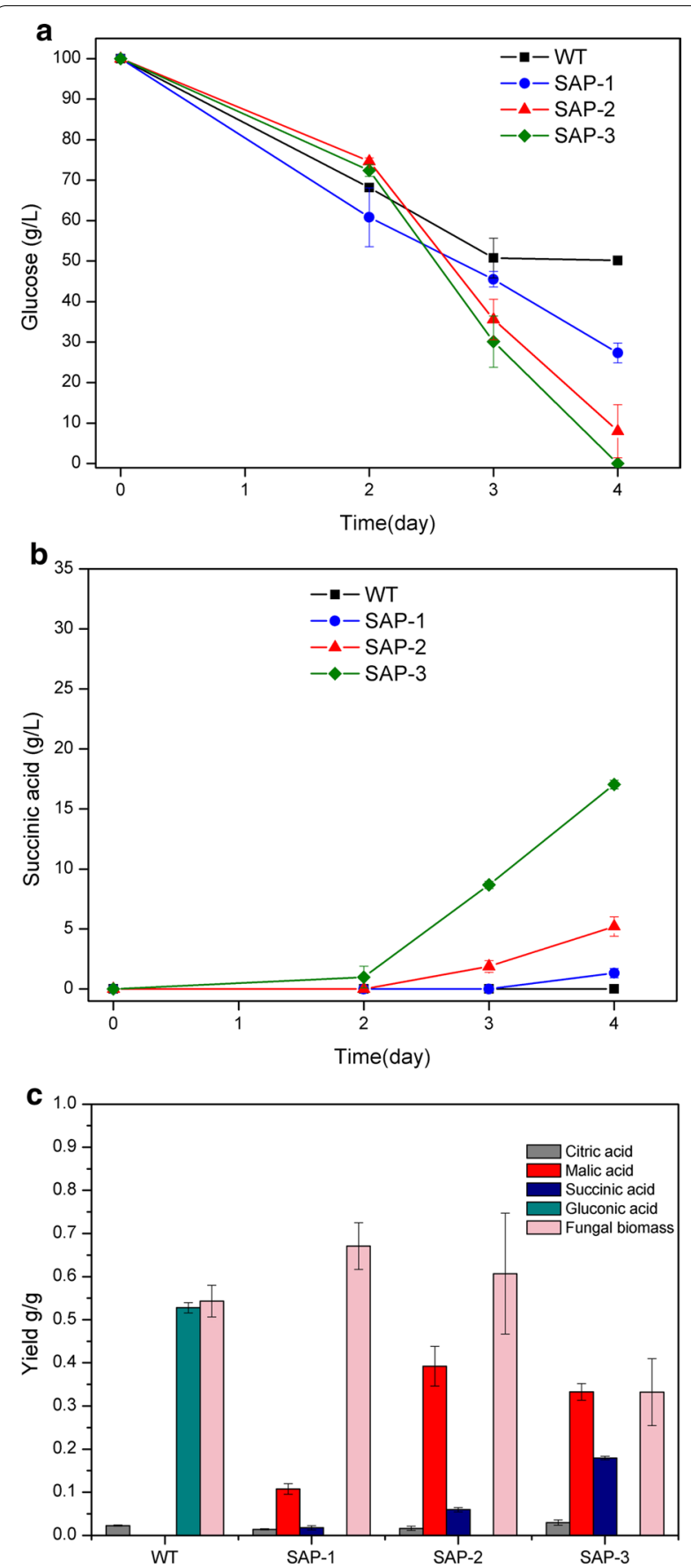

Fig. 2 Succinic acid production by the wild type and the engineered strains at $30{ }^{\circ} \mathrm{C}$. a Glucose consumption $(\mathrm{g} / \mathrm{L})$; $\mathbf{b}$ production of Succinic acid $(\mathrm{g} / \mathrm{L})$; c yields of major organic acids and fungal biomass after 4 days

biomass growth over succinic acid production; the biomass yield reached $0.76 \mathrm{~g} / \mathrm{g}$ glucose, which was around 2to 3 -fold higher than the biomass yield at the other three temperature levels (Fig. 3c).
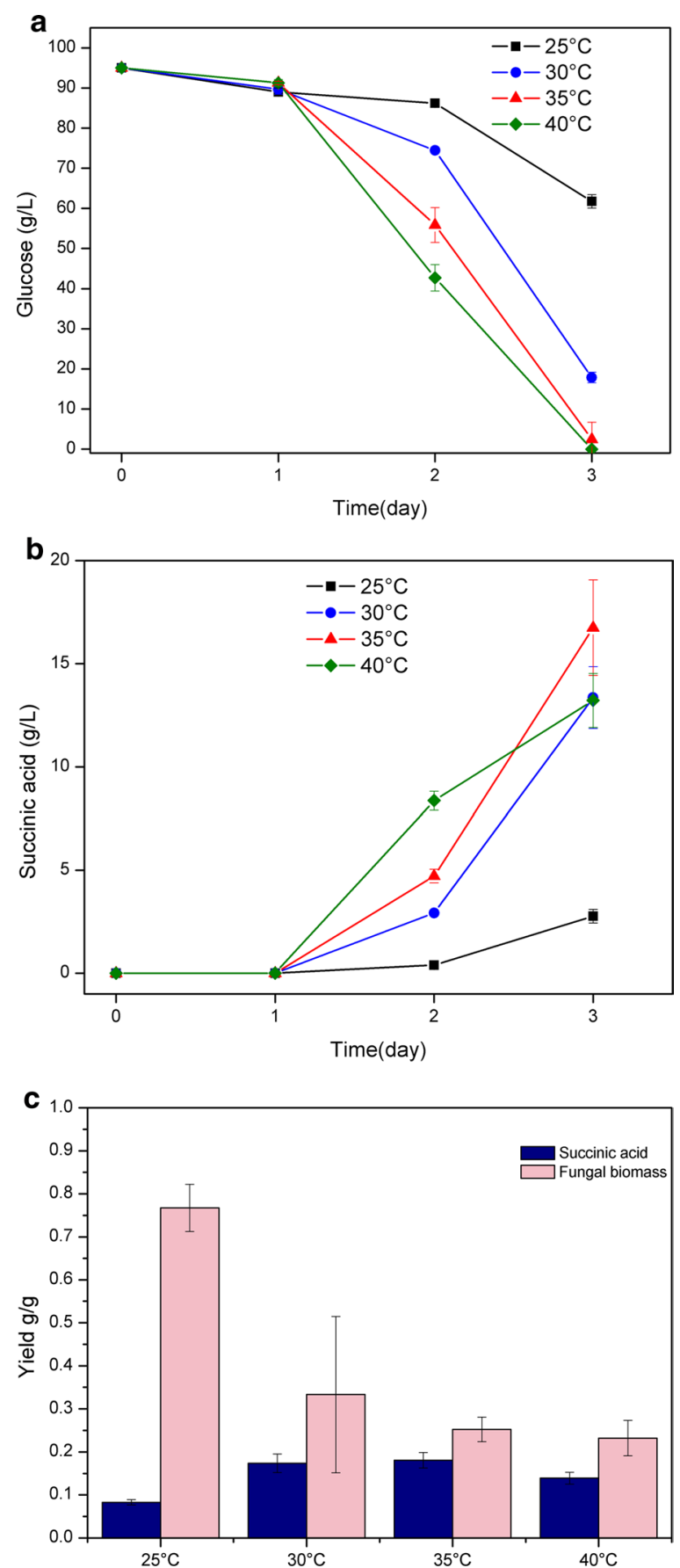

Fig. 3 Impacts of cultivation temperature on succinic acid production by the SAP-3 strain. a Glucose consumption ( $\mathrm{g} / \mathrm{L}$ ); $\mathbf{b}$ production of succinic acid ( $\mathrm{g} / \mathrm{L}$ ); c yields of succinic acid and fungal biomass after 3 days

The impacts of cultivation $\mathrm{pH}$ changes on succinic acid production were investigated using a batch culture at controlled $\mathrm{pH}$ levels. The cultivation began with a low initial $\mathrm{pH}$ at 2.5 , and after 4 days, the SAP-3 
strain consumed $14 \mathrm{~g} / \mathrm{L}$ glucose at this $\mathrm{pH}$ level, but no measurable amount of succinic acid was detected in the culture. In the following days, the culture $\mathrm{pH}$ was adjusted to different levels stepwise and maintained for 1 day. As seen in Fig. 4a, the succinic acid production began after the $\mathrm{pH}$ level increased to 3.5 and reached $0.5 \mathrm{~g} / \mathrm{L}$ with glucose consumption of $22 \mathrm{~g} / \mathrm{L}$ on day 5 . In the next 2 days, the $\mathrm{pH}$ levels were adjusted to 4.5 and 5.5, and succinic acid production increased to $1.6 \mathrm{~g} / \mathrm{L}$ and $4.1 \mathrm{~g} / \mathrm{L}$ on day 6 and 7, respectively. After day 7 , there was still $73 \mathrm{~g} / \mathrm{L}$ glucose remaining in the culture, the pH level was then lowered again to 3.5. In day 8 , the production of succinic acid by the SAP-3 strain only increased to $4.4 \mathrm{~g} / \mathrm{L}$ (Fig. 4a). Although the sugar consumption was affected due to the $\mathrm{pH}$ adjustment in the different stages of cultivation, the yield of succinic acid showed consistently the same trend that higher succinic acid yield was obtained as the $\mathrm{pH}$ level was increased. The succinic acid yield reached $0.09 \mathrm{~g} / \mathrm{g}$ glucose at $\mathrm{pH} 5.5$, and was reduced to $0.03 \mathrm{~g} / \mathrm{g}$ glucose at pH 3.5 (Fig. 4b).

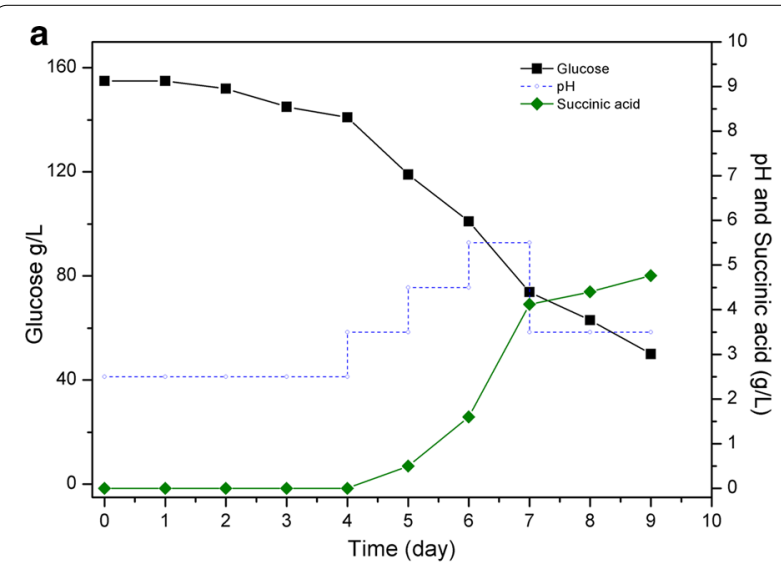

b

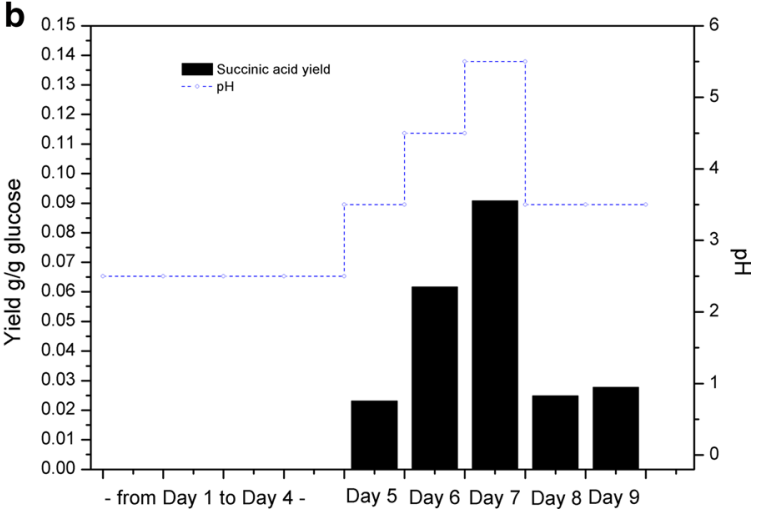

Fig. 4 Impacts of low cultivation $\mathrm{pH}$ on succinic acid production by the SAP-3 strain at $35^{\circ} \mathrm{C}$. a Glucose consumption and succinic acid production $(\mathrm{g} / \mathrm{L})$; $\boldsymbol{b}$ yield of succinic acid at different $\mathrm{pH}$ levels

\section{Succinic acid production from renewable biomass}

Two types of renewable biomass, sugar beet molasses and wheat straw hydrolysate were used as substrates for succinic acid production by the SAP-3 strain. Due to the complex compositions of these two substrates, the sugar consumption was monitored by measuring concentrations of major sugars in the substrates: sucrose, which was gradually hydrolyzed into glucose and fructose by $A$. niger in the molasses substrate, and glucose and xylose in the hydrolysate substrate. In molasses, no significant inhibitory effect was observed in the beginning of the cultivation. As seen in Fig. 5a, succinic acid production began after a short lag phase on day 1 . After 6 days, the SAP-3 strain consumed all the sucrose and produced $23 \mathrm{~g} / \mathrm{L}$ succinic acid. On the other hand, as sucrose was gradually hydrolyzed during the cultivation, it was observed that glucose and fructose were consumed at different rates. After 2 days, glucose was consumed more rapidly than fructose with a sharp increase of succinic acid production. In wheat straw hydrolysate, a longer lag phase was observed compared with the molasses medium. As seen in Fig. 5b, measurement of one potential inhibitor in the wheat straw hydrolysate, acetic acid, showed that the SAP-3 strain converted acetic acid prior to the sugar consumption in the first two days. The succinic acid production began from day 3 and reached $9 \mathrm{~g} / \mathrm{L}$ after 6 days. For sugar consumption, the SAP-3 strain was not able to utilize xylose as efficiently as glucose, where glucose was quickly depleted after day 5 , whereas, there was still $9 \mathrm{~g} / \mathrm{L}$ xylose remaining in the culture after 6 days. Due to the slow xylose consumption, succinic acid production also decreased after day 5 . However, even though the succinic acid yield from total consumption of major sugars was significantly lower in the wheat straw hydrolysate than that in molasses, the fungal biomass yields from both media were obtained at similar levels (Fig. 5c).

\section{Discussion}

In this study, we performed consecutive genetic modifications in A. niger via the RNP-based CRISPR-Cas9 system in combination with an AMA plasmid containing a dominating selectable marker. The single gene disruptions were achieved using only RNP complexes without any donor HR fragment, where gene disruption efficiencies of $12.5-38 \%$ were obtained, which was lower than other CRISPR-Cas9 systems applied in Aspergillus, e.g., the plasmid-based system [22, 23]. In vitro assembly of the RNP complex could simplify the construction of the CRISPR-Cas9 system and reduce unspecific off-target cleavage activity of Cas9 with the precise control of the Cas9 protein and gRNA in the assembly process [26]. 


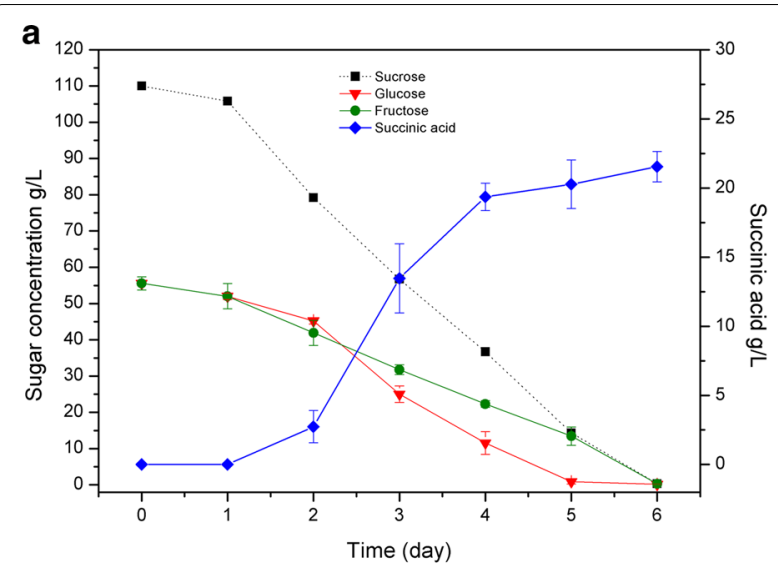

b

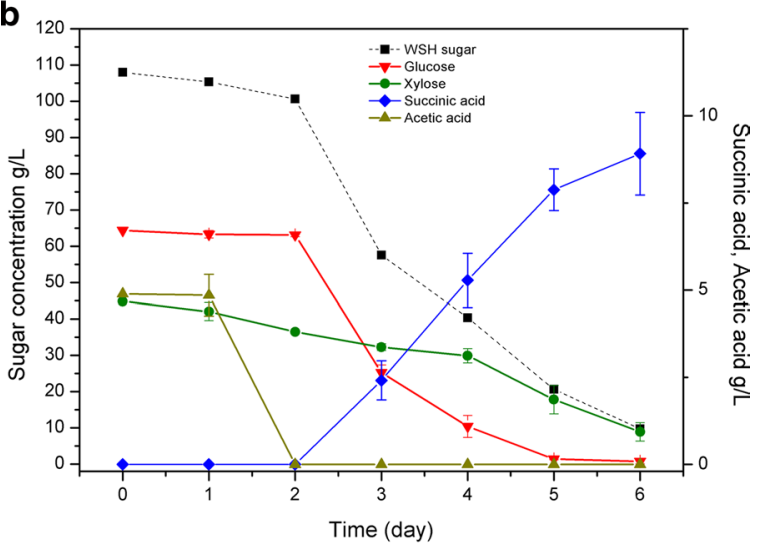

C

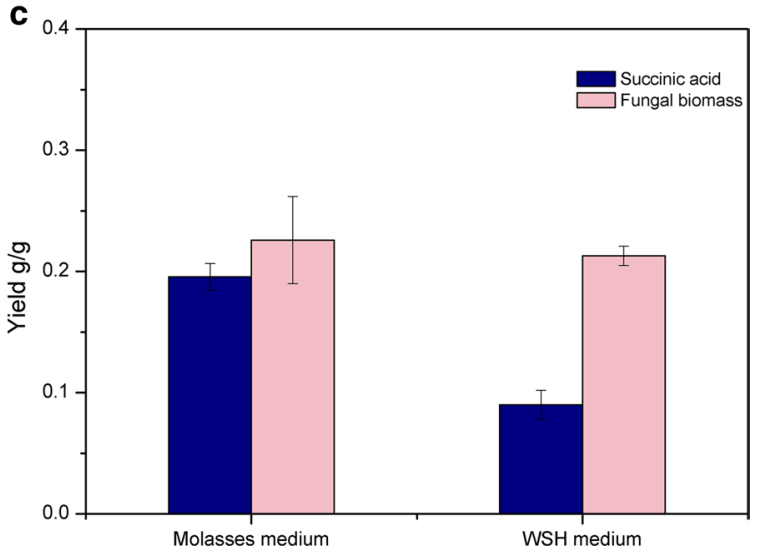

Fig. 5 Succinic acid production from sugar cane molasses and wheat straw hydrolysate by the SAP-3 strain $35^{\circ} \mathrm{C}$. a succinic acid production and consumption of major sugars in sugar beet molasses; b succinic acid production and consumption of major sugars and acetic acid in wheat straw hydrolysate; c yields of succinic acids and fungal biomass (WSH — wheat straw hydrolysate)

However, a potential limiting step in the RNP-based CRISPR-Cas9 system is the co-transformation efficiency. Since the uptake of RNP complex in our approach is not subjected to selection pressure, the in vivo concentration of RNP complex is mainly due to the competence of protoplasts and efficiency of co-transformation with the pSB-HA plasmid. Although higher molar concentrations of the RNP was used compared to the plasmid pSB-HA in the protoplast transformation, the actual amount of the RNP complex taken up by the protoplast could not be measured, which increased the uncertainties in the following process of genome editing. On the other hand, the gene replacements were also achieved via co-transformation with RNP and donor DNA containing expression cassettes. In the case of the oah gene disruption and replacement with the frd gene expression cassette, similar efficiencies were obtained (12.5\% and $18 \%)$. In this study, the gene disruption and gene replacement were carried out via different DNA repair pathways. After the DNA double-strand breaks were created by the RNP complexes, null mutations were introduced into genes through the DNA repair process in $A$. niger, which highly relies on the mutation frequency of the NHEJ pathway. The gene replacement was achieved through integration of the HR fragments into the genome via the homologous recombination pathway, the efficiency of which is naturally very low in $A$. niger [21]. Therefore, the promising gene replacement efficiencies obtained in this study showed the potential of using an additional knockout cassette for single gene disruption, in this case, the mutations in the target genes can be manipulated more precisely. To further improve the efficiency of genome editing via the RNP-based CRISPR-Cas9 system, the future efforts might be to optimize transformation systems for delivering the RNP complex together with the donor DNA fragment in combination with inactivation of NHEJ pathway, such as using a Ku-deficient strain [24].

As a robust industrial workhorse for citric acid production, $A$. niger has often been used as a good microbial platform for production of other organic acids [12]. The wild-type strain of $A$. niger is capable of accumulating high amounts of citric acid, oxalic acid and gluconic acid from glucose. Especially the latter two organic acids are produced efficiently under the similar conditions that favor succinic acid production, e.g., high glucose concentration and controlled ambient $\mathrm{pH}$ levels (from 4 to 6) [27-29]. The two genes, oah and gox, which are directly involved in production of oxalic acid and gluconic acid $[30,31]$, were disrupted in the strain SAP- 1 . The elimination of these two organic acids led to a low production of succinic acid by the SAP-1 strain, which implies that part of the carbon flux has been rerouted towards succinic acid but other limiting steps existing in the relevant pathways still restrict an efficient production. In our previous study, we revealed an important role of the $\mathrm{C}_{4}$-dicarboxylic acid transporter for succinic acid production in $A$. carbonarius, which resembles $A$. niger in many features in terms of organic acid production [19]. A 
recent study on $\mathrm{C}_{4}$-dicarboxylate transporters from different fungal species has shown the unique characteristic of AcDCT in relation to its high efficiency of exporting $\mathrm{C}_{4}$-dicarboxylic acids [32]. Therefore, we heterologously overexpressed the $\mathrm{C}_{4}$-dicarboxylic acid transporter identified from $A$. carbonarius and replaced the original dicarboxylic acid transporter of $A$. niger, which has also been reported for low export efficiency of dicarboxylic acids [15]. The further increase in succinic acid yield in strain SAP-2 compared with the SAP-1 strain indicates that the export of succinic acid is also a limiting step in efficient excretion of succinic acid in $A$. niger. Furthermore, when we overexpressed both the Acdct gene and the $f r d$ gene in strain SAP-3, a synergistic effect of these two genetic modification led to the highest succinic acid production. The soluble NADH-dependent fumarate reductase was expressed to continue the carbon flux towards succinic acid via reduction of the cytosolic precursor fumarate [33], which can normally be produced via the dehydration of malate by fumarase in the rTCA branch [34]. Although fumaric acid was not found at detectable amounts in this study, malic acid was produced by all the engineered strains. Compared with the SAP-2 strain, the SAP-3 strain produced lower amounts of malic acid but more succinic acid, which indicates that part of the carbon flux has successfully been shunted into succinic acid from malic acid. On the other hand, the lowest biomass yield in the SAP-3 strain also implies that the overexpression of FRD also affects the carbon flux between cytosolic reductive pathway and central metabolic pathways in relation with fungal biomass growth, and more carbon flux was rerouted towards organic acid production in the SAP-3 strain.

Moreover, two major cultivation parameters, $\mathrm{pH}$ and temperature, were also investigated for their impacts on succinic acid production. A. niger has favorable growth temperatures ranging from 25 to $40{ }^{\circ} \mathrm{C}$, and for citric acid production by $A$. niger, the optimal temperature is normally set to 25 to $30{ }^{\circ} \mathrm{C}$ [35]. However, our results have shown that the succinic acid production by $A$. niger favors relatively high cultivation temperatures as the highest succinic acid yield was obtained at $35{ }^{\circ} \mathrm{C}$, while the lowest cultivation temperature $25{ }^{\circ} \mathrm{C}$ decreased succinic acid production dramatically. Oppositely, the measurement of fungal biomass at different temperatures showed that the carbon flow was increased towards fungal growth instead of succinic acid production as the highest biomass yield was obtained with the lowest sugar consumption at $25{ }^{\circ} \mathrm{C}$. In the case of citric acid production, the higher temperature may cause denaturation of the key enzyme in the TCA cycle, citrate synthase, which in turn hinders the biosynthesis of citric acid [36]. Therefore, a possible explanation for low succinic acid production at low temperature is that the enzymes involved in the cytosolic reductive TCA branch, e.g., malate dehydrogenase and fumarate reductase, which normally have high optimum temperatures, exhibit lower activity at $25{ }^{\circ} \mathrm{C}$ [37-39]. The impact of culture $\mathrm{pH}$ on succinic acid production was also investigated in the batch culture where the initial $\mathrm{pH}$ was set to 2.5. As $A$. niger was able to grow in a broad range of $\mathrm{pH}$ values with steady intracellular $\mathrm{pH}$ level [40], low cultivation $\mathrm{pH}$ was commonly used for citric acid production to avoid accumulation of byproducts [9]. Fungal growth and sugar consumption were observed at $\mathrm{pH} 2.5$, and similar pellet morphology was obtained compared with the shake flask culture (Additional file 1: Table S1), but succinic acid production was not detected in measurable quantity. While the $\mathrm{pH}$ level was adjusted stepwise from 3.5 to 5.5 , succinic acid production increased gradually as seen in Fig. 4c. To further validate the impact of culture $\mathrm{pH}$ changes on succinic acid, the cultivation at $\mathrm{pH} 3.5$ was performed in the batch culture, on day 8 . Similar yields of succinic acid obtained on day 5 and 8 at $\mathrm{pH} 3.5$ showed that the succinic acid production has an instantaneous response to $\mathrm{pH}$ changes and was suppressed by low culture $\mathrm{pH}$ value, especially taking into consideration the fact that the highest succinic acid yield was obtained on day 7 , and a high quantity of glucose still remained in the culture. Since $A$. niger strains are not able to naturally produce high amounts of succinic acid, the impacts of $\mathrm{pH}$ on succinic acid production have not been examined before. Our results showed that the natural tolerance of $A$. niger to low $\mathrm{pH}$ levels did not lead to efficient succinic acid production as known for citric acid production. Compared with the reported succinic acid producers, e.g., A. succinogenes and $E$. coli, which are capable of producing $105 \mathrm{~g} / \mathrm{L}$ and $101 \mathrm{~g} / \mathrm{L}$ succinic acid from glucose medium [41], one of the major advantages for developing $A$. niger into a new fungal cell factory is to couple its excellent low $\mathrm{pH}$ tolerance with low $\mathrm{pH}$ process for succinic acid production. As it has not been observed in our engineered strains, the future challenge in strain development of $A$. niger is to identify the mechanism for low $\mathrm{pH}$ suppression and improve the efficiency of succinic acid production at low $\mathrm{pH}$ levels. The succinic acid production in $A$. niger has similar responses to ambient $\mathrm{pH}$ changes as oxalic acid production, which is normally obtained at relatively high $\mathrm{pH}$ levels (from $\mathrm{pH} 3$ to 6). Although the mechanism of $\mathrm{pH}$ regulation on oxalic acid production in A. niger is not fully understood, it has been reported that the expression levels of different genes varies at different $\mathrm{pH}$ levels via the regulation of $\mathrm{pH}$ dependent transcription factors OafA and PacC 
$[42,43]$. Therefore, further studies on the regulation of genes related to succinic acid-producing pathways may offer the path to efficient production of succinic acid at low $\mathrm{pH}$ level.

Sugar as substrate is expensive and it is of interest to find cheap sugar containing substrates for future industrial production. Therefore, two types of renewable biomasses were investigated as substrates for succinic acid production by $A$. niger; sugar beet molasses, which has been used as an industrial feedstock for citric acid production by $A$. niger for decades, and wheat straw hydrolysate, which is obtained from agro-industrial lignocellulosic waste after pretreatment and enzymatic hydrolysis. One of the major challenges to apply renewable biomasses in biological processes is the inhibitory effects on microbial growth due to the chemical composition of the biomass, especially after harsh pre-treatments of lignocellulosic biomass. Compared with the defined medium, a significant inhibitory effect was observed only in the wheat straw hydrolysate but not in the culture containing molasses. Our previous study has shown that a number of inhibitors, especially acetic acid, in the hydrolysate can suppress the spore germination and mycelial growth in the early stage of the fungal cultivation [44]. Normally these inhibitors are converted in the lag phase before sugar consumption begin, which is consistent with the phenomenon that the acetic acid consumption preceded sugar consumption in the wheat straw hydrolysate in this study. In molasses medium, as $A$. niger naturally can resist the potential inhibitors in molasses and efficiently use molasses sugar for organic acid production, the SAP-3 strain produced similar amount of succinic acid from molasses compared with the glucose defined medium. On the other hand, the low succinic acid production from wheat straw hydrolysate indicates the challenges in the utilization of this type of renewable biomass due to their complex composition and the pre-treatment effects. Although similar amounts of sugar were used in the media containing molasses and the wheat straw hydrolysate, the carbohydrate compositions were still different. In molasses, sucrose exists as the major sugar component, which is normally hydrolyzed into glucose and fructose and utilized by $A$. niger as carbon sources. In the wheat straw hydrolysate, the two major types of sugars are glucose and xylose. The consumption of these C6 and C5 sugars shows that glucose was utilized more efficiently than fructose and xylose for succinic acid production. When glucose was present at high concentration in the media, the SAP-3 strain was capable of producing high amounts of succinic acid, but the succinic acid production slowed down when the glucose was depleted. This implies the importance of improving the efficiency of succinic acid production from different types of sugars present in renewable biomass for future pathway engineering of $A$. niger.

\section{Conclusions}

In this study, we performed consecutive genetic manipulations with the RNP-based CRISPR-Cas9 system in $A$. niger ATCC 1015 and improved succinic acid production through pathway engineering. The cultivation temperature and ambient $\mathrm{pH}$ value were studied for their effects on succinic acid production, and it is shown that the relatively high temperature $\left(35^{\circ} \mathrm{C}\right)$ and $\mathrm{pH}$ level (5.5) in the cultivation benefitted succinic acid production. Furthermore, two types of renewable biomasses, sugar beet molasses and wheat straw hydrolysate, were investigated for their potential to be substrates for succinic acid production by $A$. niger. Since succinic acid production was obtained from both types of substrates at different yields, the feasibility of using renewable biomass for bio-based production of succinic acid by $A$. niger is proven.

\section{Methods}

\section{Strains and growth conditions}

The A. niger strain ATCC1015 and all the engineered strains (Table 2) were cultivated on potato dextrose agar plates at $30{ }^{\circ} \mathrm{C}$ for spore production. For genomic DNA extraction and preparation of protoplast, all the strains were cultivated in yeast extract peptone dextrose medium (glucose, $20 \mathrm{~g} / \mathrm{L}$; yeast extract, $10 \mathrm{~g} / \mathrm{L}$; peptone, $20 \mathrm{~g} / \mathrm{L})$ at $30^{\circ} \mathrm{C}$ overnight.

\section{Plasmid construction}

The Cas9 and gRNA expression cassettes in the plasmid pFC332 (constructed and donated by Technical University of Denmark) were removed by restriction enzymes $B g l \mathrm{II}$ and $\mathrm{BamHI}$, and the remaining backbone was selfligated to form plasmid pSB-HA, which contains the AMA1 sequences together with the $h p h$ resistance gene (Additional file 1: Figure S1).

The glucose oxidase encoding gene gox, oxaloacetate hydrolase encoding gene oah and the dicarboxylate

\begin{tabular}{|c|c|}
\hline Strain name & Description \\
\hline$\Delta g o x$ strain $^{a}$ & $\Delta g o x$ \\
\hline SAP-1 & $\Delta g o x, \Delta o a h$ \\
\hline SAP-2 & $\triangle g o x, \triangle o a h, \triangle A n d c t: . g p d A p-A c d c t-t r p C t$ \\
\hline SAP-3 & $\begin{array}{l}\Delta g o x, \Delta o a h:: g p d A p-f r d-t r p C t, \Delta A n d c t:: \\
\text { gpdAp-Acdct-trpCt }\end{array}$ \\
\hline
\end{tabular}

a The $\Delta g o x$ strain was constructed and used only as the parental strain for deriving strains SAP-1, 2 and 3 in this study 
transporter encoding gene Andct were identified in the JGI genome database $A$. niger ATCC 1015 v4 (Additional file 1: Table S3). For insertion of the upstream and downstream homologous regions of genes $(\sim 500 \mathrm{bp}$ for each region), oah and Andct, individually into expression vectors, two DNA fragments were amplified via PCR from the wild-type genomic DNA with primers OahFw1OahRv1 and AnDctFw1-AnDctRv1, respectively (Additional file 1: Table S4). The DNA fragments were then cloned individually into the pJET1.2/blunt cloning vector according to manufacturer's protocol (ThermoFisher ${ }^{\circledR}$ ). The resulting HR-containing plasmids were linearized via reverse PCR with primer AnDctFw2/AnDctRv2 and OahFw2/OahRv2 for the following cloning steps. For overexpression of gene Acdct (Genbank accession no. KY178298) and frd (Genbank accession no. KT026107) in $A$. niger, the AcDCT and FRD expression cassettes were amplified via PCR from a previously constructed plasmid pSBe3Dct and pSBe1Frd, respectively, with corresponding primers. The two expression cassettes were then cloned to corresponding HR-containing plasmids using NEB Gibson assembly kit according the manufacturer's protocol. All the resulting vectors were verified by DNA sequencing.

\section{RNP assembly and protoplast transformation}

All the crRNA sequences were designed using IDT $^{\circledR}$ online CRISPR-Cas9 guide RNA design tool according to the gene sequences identified in the JGI genome database A. niger ATCC 1015 v4 (Additional file 1: Table S3). Cas9 proteins, crRNA and tracrRNA were synthesized and delivered by IDT and the in vitro RNP assembly was carried out as previously described [25]. The final concentration of RNP complex in the assembly mix was $15 \mu \mathrm{M}$.

The preparation of protoplasts was carried out as previously described [45]. $100 \mu \mathrm{L}$ protoplast suspension with concentration of $2 \times 10^{7}$ protoplasts $/ \mathrm{mL}$ was aliquoted in sterile Eppendorf tubes and used in protoplast transformation. For gene disruption, around $2.5 \mu \mathrm{g}$ plasmid pSB-HA and $5 \mu \mathrm{L}$ assembled RNP complex (within a total volume of $10 \mu \mathrm{L}$ ) were added in each transformation reaction. Prior to transformation, the dct overexpression cassette was amplified from the corresponding overexpression vector using primers AnDctFw1 and AnDctRv1. For gene overexpression, $2.5 \mu \mathrm{g}$ plasmid pSB-HA, around $7 \mu \mathrm{g}$ overexpression cassette/vectors and $5 \mu \mathrm{L}$ assembled RNP complex (in a total volume of $10 \mu \mathrm{L}$ ) were added to each transformation reaction. All the components were gently mixed in an Eppendorf tube and placed on ice for $15 \mathrm{~min}$. Next, the transformation mixture was incubated at room temperature for $15 \mathrm{~min}$ after which $1 \mathrm{~mL}$ $40 \%$ PEG4000 solution was added into the tube. The following procedure of transformation was performed as previously described [45]. All the transformation plates contained $200 \mu \mathrm{g} / \mathrm{mL}$ hygromycin for selection of transformants. After 3-4 days, the transformants were transferred individually to PDA plates and grown at $30{ }^{\circ} \mathrm{C}$ for the screening test.

\section{Validation of genetic modifications and removal of selectable marker}

For gene disruption, the genome regions containing the RNP recognition sites were amplified via PCR using Hi-Fi Q5 polymerase $\left(\mathrm{NEB}^{\circledR}\right)$ with corresponding primers (Additional file 1: Table S4), the obtained PCR amplicons were purified and sequenced to screen mutations in the genes. For gene overexpression, integration of the expression cassette in target regions of the genome were verified by amplifying the fragments with expected sizes in PCR with Taq polymerase. For removal of selectable marker, the transformants were overgrown in PDA plates without hygromycin for 4-5 days and transferred to a new PDA plate by streaking with low amounts of spores. After overnight cultivation at $30{ }^{\circ} \mathrm{C}$, single colonies were isolated and transferred to new PDA plates again for cultivation. After sporulation, the spores were harvested and inoculated to PDA plates containing $200 \mu \mathrm{g} / \mathrm{mL}$ hygromycin. The isolated colonies, which were not able to grow in hygromycin-containing plates, were selected and preserved for the further experiments.

\section{Succinic acid production}

For comparing succinic acid production between the wild type and the selected transformants, the cultivation was carried out in 250-mL Erlenmeyer flasks containing $50 \mathrm{~mL}$ succinic acid production medium at $30{ }^{\circ} \mathrm{C}$ with agitation speed of $200 \mathrm{rpm}$. The SAP medium consisted of glucose, $100 \mathrm{~g} / \mathrm{L} ; \mathrm{NH}_{4} \mathrm{NO}_{3}, 2.5 \mathrm{~g} / \mathrm{L} ; \mathrm{KH}_{2} \mathrm{PO}_{4}, 0.5 \mathrm{~g} / \mathrm{L}$; $\mathrm{MgSO}_{4} 7 \mathrm{H}_{2} \mathrm{O}, 0.6 \mathrm{~g} / \mathrm{L} ; \mathrm{CaCl}_{2} 2 \mathrm{H}_{2} \mathrm{O}, 0.05 \mathrm{~g} / \mathrm{L} ; \mathrm{ZnSO}_{4}$, $0.0015 \mathrm{~g} / \mathrm{L} ; \mathrm{FeSO}_{4} 7 \mathrm{H}_{2} \mathrm{O}, 0.1 \mathrm{~g} / \mathrm{L}$; biotin, $2 \times 10^{-5} \mathrm{~g} / \mathrm{L}$ and $\mathrm{CaCO}_{3}, 80 \mathrm{~g} / \mathrm{L}$. Calcium carbonate was used as a $\mathrm{pH}-$ buffering reagent in shake flasks to neutralize the organic acids produced during the cultivation as previously described $[15,19]$. For studying the impact of cultivation temperature on succinic acid production, the cultivation was carried out in the same set-up as described above at temperatures set at $25,30,35$ and $40{ }^{\circ} \mathrm{C}$. For succinic acid production from renewable biomasses, sugar beet molasses and wheat straw hydrolysate were filter sterilized and supplemented with $\mathrm{NH}_{4} \mathrm{NO}_{3}, 0.2 \mathrm{~g} / \mathrm{L} ; \mathrm{KH}_{2} \mathrm{PO}_{4}, 0.1 \mathrm{~g} / \mathrm{L}$; $\mathrm{MgSO}_{4} 7 \mathrm{H}_{2} \mathrm{O}, 0.3 \mathrm{~g} / \mathrm{L} ; \mathrm{FeSO}_{4} 7 \mathrm{H}_{2} \mathrm{O}, 0.05 \mathrm{~g} / \mathrm{L}$; biotin, $2 \times 10^{-5} \mathrm{~g} / \mathrm{L}$ and $\mathrm{CaCO}_{3}, 80 \mathrm{~g} / \mathrm{L}$. The final concentrations of sugars were $110 \mathrm{~g} / \mathrm{L}$ sucrose in the molasses medium and $64 \mathrm{~g} / \mathrm{L}$ glucose and $45 \mathrm{~g} / \mathrm{L}$ xylose in the wheat straw hydrolysate medium. In all the cultivations in shake 
flasks, freshly harvested spores were used and inoculated at concentration of $2 \times 10^{5}$ spores $/ \mathrm{mL}$.

Succinic acid production with controlled $\mathrm{pH}$ conditions was performed in $1.5 \mathrm{~L}$ medium in a 5 - $\mathrm{L}$ bioreactor. The medium consisted of glucose, $150 \mathrm{~g} / \mathrm{L}, \mathrm{NH}_{4} \mathrm{NO}_{3}$, $2.5 \mathrm{~g} / \mathrm{L} ; \mathrm{KH}_{2} \mathrm{PO}_{4}, 0.5 \mathrm{~g} / \mathrm{L} ; \mathrm{MgSO}_{4} 7 \mathrm{H}_{2} \mathrm{O}, 0.6 \mathrm{~g} / \mathrm{L} ; \mathrm{CaCl}_{2}$ $2 \mathrm{H}_{2} \mathrm{O}, 0.05 \mathrm{~g} / \mathrm{L} ; \mathrm{ZnSO}_{4}, 0.0015 \mathrm{~g} / \mathrm{L} ; \mathrm{FeSO}_{4} 7 \mathrm{H}_{2} \mathrm{O}, 0.1 \mathrm{~g} / \mathrm{L}$ and biotin, $2 \times 10^{-5} \mathrm{~g} / \mathrm{L}$. The temperature and agitation speed were set to $35^{\circ} \mathrm{C}$ and $600 \mathrm{rpm}$, and inlet air-flow rate was maintained at $1 \mathrm{vvm}$. The $\mathrm{pH}$ was adjusted and maintained by adding $5 \mathrm{M} \mathrm{HCl}$ solution and alkaline solution containing $2 \mathrm{M} \mathrm{NaCO}_{3}$ and $1 \mathrm{M} \mathrm{NaOH}$. The spores of the transformant SAP-3 were inoculated at final concentration of $2 \times 10^{5}$ spores $/ \mathrm{mL}$.

\section{HPLC analysis and fungal biomass measurement}

For analysis of organic acids, all the samples were acidified with $50 \%(\mathrm{v} / \mathrm{v})$ sulfuric acid and incubated at $80{ }^{\circ} \mathrm{C}$ for $15 \mathrm{~min}$. The acidified samples were centrifuged at $11,000 \mathrm{rpm}$ for $1 \mathrm{~min}$, and the supernatant was filtered with a $0.45-\mu \mathrm{m}$ filter and used for HPLC analysis. For analysis of sugar, the samples were prepared in the same process as described above without the acidification step. Analysis of organic acids was carried out with an Aminex $87 \mathrm{H}$ column (Biorad ${ }^{\circledR}$ ) at $60^{\circ} \mathrm{C}$ by using a HPLC mobile phase $\left(5 \mathrm{mM} \mathrm{H}_{2} \mathrm{SO}_{4}\right)$ at a flow rate of $0.6 \mathrm{~mL} / \mathrm{min}$, and analysis of sugars was carried out with an Aminex 87P column (Biorad ${ }^{\circledR}$ ) at $80^{\circ} \mathrm{C}$ by using a HPLC mobile phase (ultrapure water) at a flow rate of $0.5 \mathrm{~mL} / \mathrm{min}$.

For fungal biomass measurements, $5 \mathrm{~mL}$ culture was acidified and washed with $1 \mathrm{~N} \mathrm{HCl}$ on a pre-dried $0.22 \mu \mathrm{m}$ filter until the $\mathrm{pH}$ in the flow-through was lower than 2 . The filtered fungal biomass was then thoroughly washed with distilled water and dried on the filter paper at $100{ }^{\circ} \mathrm{C}$ for $48 \mathrm{~h}$ before weighing.

\section{Supplementary Information}

The online version contains supplementary material available at https://doi. org/10.1186/s13068-020-01850-5.

Additional file 1: Table S1. Strain morphology in succinic acid production. Table S2. The initial and final $\mathrm{pH}$ value in the cultures at different cultivation temperatures. Table S3. Genes manipulated in this study using corresponding gRNAs. Table S4. Primers used in this study. Figure S1. Plasmids used in this study.

\section{Abbreviations}

FRD: Fumarate reductase; RNP: Ribonucleoprotein; SAP: Succinic acid producing; rTCA branch: Reductive tricarboxylic acid branch.

\section{Acknowledgement}

We thank laboratory technician Gitte Hinz-Berg and Stefan Ulrich Heiske for HPLC analysis.

\section{Authors' contributions}

LY has made substantial contributions to the project plan, the experimental design, and performed identification of transporter gene, construction of plasmids and transformants, biochemical characterization (fermentation and enzyme assays), data analysis and drafted the manuscript. MMH and RSH performed gene cloning and construction of some of the plasmids and transformants, and edited the manuscript. JV established the transformation system compatible with the RNP complex. SB and JEA performed construction of some of the plasmids and transformants. ML and PSL planned the project and edited the manuscript. All authors read and approved the final manuscript.

\section{Funding}

Financial support from the Danish Strategic Research Program MycoFuelChem (DSF Grant No. 11-116803) is acknowledged.

\section{Availability of data and materials}

All the data analyzed during this study have been included in this published article.

Ethics approval and consent to participate

This study does not contain any experiment with human participants or animals performed by any of the authors.

\section{Consent for publication}

All authors consent the manuscript for publication in Biotechnology for Biofuels.

\section{Competing interests}

The authors declare that they have no conflict of interest.

\section{Author details}

${ }^{1}$ Section for Sustainable Biotechnology, Department of Chemistry and Bioscience, Aalborg University Copenhagen, A. C. Meyers Vænge 15, 2450 Copenhagen SV, Denmark. ${ }^{2}$ Section of Microbiology, Department of Biology, University of Copenhagen, Universitetsparken 15, 2100 Copenhagen, Denmark. ${ }^{3}$ Section of Cell and Neurobiology, Department of Biology, University of Copenhagen, Universitetsparken 15, 2100 Copenhagen, Denmark. ${ }^{4}$ Disease Data Intelligence, Department of Health Technology Bioinformatics, Technical University of Denmark, Bldg. 208, 2800 KemitorvetKgs. Lyngby, Denmark.

Received: 10 September 2020 Accepted: 4 December 2020

Published online: 14 December 2020

\section{References}

1. Holladay J, Bozell J, White J, Johnson D: Top value-added chemicals from biomass. DOE Report PNNL-16983 (website: http://chembioprocess.pnl. gov/staff/staff_info.asp 2007.

2. Cok B, Tsiropoulos I, Roes AL, Patel MK. Succinic acid production derived from carbohydrates: an energy and greenhouse gas assessment of a platform chemical toward a bio-based economy. Biofuel Bioprod Biorefining. 2014;8(1):16-29.

3. Ahn JH, Jang Y, Lee SY. Production of succinic acid by metabolically engineered microorganisms. Curr Opin Biotechnol. 2016;42:54-66.

4. Debabov V. Prospects for biosuccinic acid production. Appl Biochem Microbiol. 2015;51(8):787-91.

5. Song H, Lee SY. Production of succinic acid by bacterial fermentation. Enzyme Microb Technol. 2006;39(3):352-61.

6. Yuzbashev TV, Yuzbasheva EY, Laptev IA, Sobolevskaya TI, Vybornaya TV, Larina AS, Gvilava IT, Antonova SV, Sineoky SP. Is it possible to produce succinic acid at a low pH? Bioeng Bugs. 2011;2:2.

7. Sengupta S, Jaiswal D, Sengupta A, Shah S, Gadagkar S, Wangikar PP. Metabolic engineering of a fast-growing cyanobacterium Synechococcus elongatus PCC 11801 for photoautotrophic production of succinic acid. Biotechnol Biofuels. 2020;13:1-18.

8. Li C, Gao S, Li X, Yang X, Lin CSK. Efficient metabolic evolution of engineered Yarrowia lipolytica for succinic acid production using a glucosebased medium in an in situ fibrous bioreactor under low-pH condition. Biotechnol Biofuels. 2018;11(1):236. 
9. Papagianni M. Advances in citric acid fermentation by Aspergillus niger: Biochemical aspects, membrane transport and modeling. Biotechnol Adv. 2007;25(3):244-63.

10. Lu F, Ping K, Wen L, Zhao W, Wang Z, Chu J, Zhuang Y. Enhancing gluconic acid production by controlling the morphology of Aspergillus niger in submerged fermentation. Process Biochem. 2015;50(9):1342-8.

11. Show PL, Oladele KO, Siew QY, Aziz Zakry FA. Lan JC-, Ling TC: Overview of citric acid production from Aspergillus niger. Front Life Sci. 2015:8(3):271-83.

12. Yang $L$, Lübeck $M$, Lübeck PS. Aspergillus as a versatile cell factory for organic acid production. Fungal Biol Rev. 2017;31(1):33-49.

13. Dave KK, Punekar NS. Expression of lactate dehydrogenase in Aspergillus niger for L-lactic acid production. PLoS ONE. 2015;10(12):e0145459.

14. van der Straat $L$, Vernooij M, Lammers M, van den Berg W, Schonewille T, Cordewener J, van der Meer I, Koops A, De Graaff LH. Expression of the Aspergillus terreus itaconic acid biosynthesis cluster in Aspergillus niger. Microb Cell Fact. 2014;13:1.

15. Xu Y, Shan L, Zhou Y, Xie Z, Ball AS, Cao W, Liu H. Development of a CreloxP-based genetic system in Aspergillus niger ATCC1015 and its application to construction of efficient organic acid-producing cell factories. Appl Microbiol Biotechnol. 2019;103(19):8105-14.

16. de Jongh WA, Nielsen J. Enhanced citrate production through gene insertion in Aspergillus niger. Metab Eng. 2008;10(2):87-96.

17. Meijer S, Otero J, Olivares R, Andersen MR, Olsson L, Nielsen J. Overexpression of isocitrate lyase - glyoxylate bypass influence on metabolism in Aspergillus niger. Metab Eng. 2009;11(2):107-16.

18. Yang $L$, Lübeck M, Lübeck PS. Effects of heterologous expression of phosphoenolpyruvate carboxykinase and phosphoenolpyruvate carboxylase on organic acid production in Aspergillus carbonarius. J Ind Microbiol Biotechnol. 2015;42(11):1533-45.

19. Yang L, Christakou E, Vang J, Lübeck M, Lübeck PS. Overexpression of a C4-dicarboxylate transporter is the key for rerouting citric acid to C4-dicarboxylic acid production in Aspergillus carbonarius. Microb Cell Fact. 2017;16:1

20. Yang L, Lübeck M, Ahring BK, Lübeck PS. Enhanced succinic acid production in Aspergillus saccharolyticus by heterologous expression of fumarate reductase from Trypanosoma brucei. Appl Microbiol Biotechnol. 2016;100(4):1799-809.

21. Meyer V. Genetic engineering of filamentous fungi-progress, obstacles and future trends. Biotechnol Adv. 2008;26(2):177-85.

22. Nødvig CS, Nielsen JB, Kogle ME, Mortensen UH. A CRISPR-Cas9 system for genetic engineering of filamentous fungi. PLoS ONE. 2015;10:7.

23. Kuivanen J, Korja V, Holmström S, Richard P. Development of microtiter plate scale CRISPR/Cas9 transformation method for Aspergillus niger based on in vitro assembled ribonucleoprotein complexes. Fungal Biol Biotechnol. 2019;6(1):1-12.

24. Song L, Ouedraogo J, Kolbusz M, Nguyen TTM, Tsang A. Efficient genome editing using tRNA promoter-driven CRISPR/Cas9 gRNA in Aspergillus niger. PLOS ONE. 2018;13(8):e0202868.

25. Al-Abdallah Q, Ge W, Fortwendel JR: A Simple and Universal System for Gene Manipulation in Aspergillus fumigatus: In Vitro-Assembled Cas9Guide RNA Ribonucleoproteins Coupled with Microhomology Repair Templates. mSphere 2017, 2: 6. Doi: https://doi.org/10.1128/mSphe re.00446-17 (eCollection 2017 Nov-Dec)

26. Vakulskas CA, Behlke MA. Evaluation and reduction of CRISPR off-target cleavage events. Nucleic Acid Therap. 2019;29(4):167-74.

27. Mandal SK, Banerjee PC. Submerged production of oxalic acid from glucose by immobilized Aspergillus niger. Process Biochem. 2005;40(5):1605-10

28. Singh OV, Jain RK, Singh RP. Gluconic acid production under varying fermentation conditions by Aspergillus niger. J Chem Technol Biotechnol. 2003:78(2-3):208-12.
29. Beauprez JJ, De Mey M, Soetaert WK. Microbial succinic acid production: Natural versus metabolic engineered producers. Process Biochem. 2010:45(7):1103-14

30. Ruijter GJG, Van De Vondervoort PJI, Visser J. Oxalic acid production by Aspergillus niger: An oxalate-non-producing mutant produces citric acid at $\mathrm{pH} 5$ and in the presence of manganese. Microbiology. 1999;145(9):2569-76.

31. Kriechbaum M, Heilmann HJ, Wientjes FJ, Hahn M, Jany K, Gassen HG, Sharif F, Alaeddinoglu G. Cloning and DNA sequence analysis of the glucose oxidase gene from Aspergillus niger NRRL-3. FEBS Lett. 1989;255(1):63-6.

32. Darbani B, Stovicek V, van der Hoek SA, Borodina I. Engineering energetically efficient transport of dicarboxylic acids in yeast Saccharomyces cerevisiae. Proc Natl Acad Sci USA. 2019;116(39):19415-20.

33. Besteiro S, Biran M, Biteau N, Coustou V, Baltz T, Canioni P, Bringaud F. Succinate secreted by Trypanosoma brucei is produced by a novel and unique glycosomal enzyme NADH-dependent fumarate reductase. J Biol Chem. 2002;277(41):38001-12.

34. Tong Z, Zheng X, Tong Y, Shi Y, Sun J. Systems metabolic engineering for citric acid production by Aspergillus niger in the post-genomic era. Microb Cell Fact. 2019;18(1):1-15

35. Ali S: Temperature optima for citric acid accumulation by Aspergillus niger. International Journal of Biotechnology (Pakistan) 2002.

36. Ramesh T, Kalaiselvam M. An experimental study on citric acid production by Aspergillus niger using Gelidiella acerosa as a substrate. Indian J Microbiol. 2011;51(3):289-93.

37. Fields PA, Rudomin EL, Somero GN. Temperature sensitivities of cytosolic malate dehydrogenases from native and invasive species of marine mussels (genus Mytilus): sequence-function linkages and correlations with biogeographic distribution. J Exp Biol. 2006;209(Pt 4):656-67.

38. Khandekar SS, Eirich LD. Purification and characterization of an anabolic fumarate reductase from Methanobacterium thermoautotrophicum. Appl Environ Microbiol. 1989;55(4):856-61.

39. Miura A, Kameya M, Arai H, Ishii M, Igarashi Y. A soluble NADH-dependent fumarate reductase in the reductive tricarboxylic acid cycle of Hydrogenobacter thermophilus TK-6. J Bacteriol. 2008;190(21):7170-7.

40. Hesse SJ, Ruijter GJG, Dijkema C, Visser J. Intracellular pH homeostasis in the filamentous fungus Aspergillus niger. Eur J Biochem. 2002;269(14):3485-94.

41. Cheng K, Zhao X, Zeng J, Zhang J. Biotechnological production of succinic acid: Current state and perspectives. Biofuels Bioproducts Biorefining. 2012;6(3):302-18.

42. Poulsen L, Andersen MR, Lantz AE, Thykaer J. Identification of a transcription factor controlling $\mathrm{pH}$-dependent organic acid response in Aspergillus niger. PLOS ONE. 2012;7:12.

43. Andersen MR, Lehmann L, Nielsen J. Systemic analysis of the response of Aspergillus niger to ambient pH. Genome Biol. 2009;10:5.

44. Yang L, Lübeck M, Souroullas K, Lübeck PS. Co-consumption of glucose and xylose for organic acid production by Aspergillus carbonarius cultivated in wheat straw hydrolysate. World J Microbiol Biotechnol. 2016;32(4):57.

45. Yang $L$, Lübeck M, Lübeck PS. Deletion of glucose oxidase changes the pattern of organic acid production in Aspergillus carbonarius. AMB Express. 2014;4:1

\section{Publisher's Note}

Springer Nature remains neutral with regard to jurisdictional claims in published maps and institutional affiliations. 